\title{
PENGGUNAAN KARBON AKTIF DARI AMPAS TEBU SEBAGAI ADSORBEN ZAT WARNA PROCION MERAH LIMBAH CAIR INDUSTRI SONGKET
}

\author{
Melyza Fitri Permanda Sari ${ }^{\mathrm{a}}$, Puji Loekitowati ${ }^{\mathrm{b}}$, Risfidian Mohadi ${ }^{\mathrm{b}}$ \\ ${ }^{a}$ Program Pengelolaan Lingkungan, Pascasarjana Universitas Sriwijaya, Jl. Padang Selasa 524, Bukit Besar, \\ Palembang 30139_melyzafitrips@gmail.com \\ ${ }^{b}$ Departemen Kimia, Fakultas Matematika dan Ilmu Pengetahuan Alam, Universitas Sriwijaya, Palembang 30128
}

\begin{abstract}
Telah dilakukan penelitian penggunaan karbon aktif dari ampas tebu untuk menyerap zat warna procion merah dari limbahindustri songket. Pembuatan karbon aktif dilakukan dengan proses karbonisasi pada temperatur $450^{\circ} \mathrm{C}$ selama 2 jam. Karbon aktif yang dihasilkan dilakukan karakterisasi FTIR untuk mengetahui gugus fungsinya serta karakterisasi BET untuk mengetahui luas permukan. Kondisi optimum adsorpsi karbon aktif dari ampas tebu terhadap procion merah dilakukan dengan variabel waktu kontak, berat karbon aktif, dan pH. Hasil karakterisasi FTIR pada karbon aktif dari ampas tebu memiliki gugus fungsi -CO-danOH, sedangkan karakterisasi BET karbon aktif dari ampas tebu sebesar 29,2 $\mathrm{m}^{2} / \mathrm{g}$. Kondisi optimum adsorpsi karbon aktif dari ampas tebu diperoleh pada waktu kontak 90 menit dengan berat karbon aktif 0,1 g dan pH optimum 5 pada $50 \mathrm{~mL}$ zat warna procion merah berkonsentrasi $20 \mathrm{mg} / \mathrm{L}$. Adsorpsi isotermal Langmuir menunjukkan serapan maksisum 0,45 mg/g dan energi sebesar 4,35 $\mathrm{kJ} / \mathrm{mol}$ Efektifitas penyerapan zat warna procion merah dari limbah cair industri songket oleh karbon aktif dari ampas tebu dalam kondisi optimum, sebesar 76,3\%.
\end{abstract}

Keywords: karbon aktif, ampas tebu, procion merah, songket Palembang, adsorpsi isotermal

(Diterima: 10-06-2016; Disetujui: 29-12-2016

\section{Pendahuluan}

Songket merupakan kain khas Sumatera Selatan, Dinas Perindustrian, Perdagangan dan Korperasi Kota Palembang mencatat, pada tahun 2011 sekitar 150 pemilik usaha kerajinan songket dan pada tahun 2013 tercatat sebanyak 230 orang memiliki usaha kerajinan kain songket (Hariani, 2013). Pencelupan benang kedalam zat warna sintetis merupakan salah satu proses pembuatan kain songket. Pewarna sintetik digunakan untuk menambah tampilan pada kain songket. Zat warna sintetis memiliki struktur kimia yang sulit terurai (Utomo et al., 2015), oleh karena itu apabila dibuang ke perairan menyebabkan karsinogenik, dermatis, alergika, iritasi kulit, umumnya memiliki LD50 sebesar 200-500 mg/L per berat badan mencit (Hariani, 2013). Purwaningrum et al., (2013) dalam penelitiannya mengatakan bahwa kandungan zat warna procion dalam limbah cair industri songket sebesar 1928,31 mg/L dan dari hasil analisis tehadap limbah industri songket yang ada di palembang menunjukkan kandungan COD antara 2960-4066 mg/L, sementara Said (2008) mendapati nilai COD limbah cair yang di hasilkan pada salah satu industri songket adalah sebesar 4993,8 mg/L sedangkan BOD antara 885-1275 $\mathrm{mg} / \mathrm{L}$ (Hariani, 2013).

Industri songket umumnya merupakan industri kecil (home industry) sehingga tidak memiliki sistem pengolahan limbah, oleh karena itu diperlukan cara untuk menangani limbah cair dari industri agar tak berdampak terhadap lingkungan. Adsorpsi menggunakan karbon aktif adalah salah satu cara yang potensial dalam mengatasi limbah cair oleh zat warna.
Bahan dasar karbon aktif adalah material organik dengan kandungan karbon yang tinggi, seperti ampas tebu yang memiliki kandungan selulosa lebih dari 30\%.Ampas tebu merupakan limbah bagi pabrik gula yang dapat digunakan sebagai penjernih perairan yang kotor (Kusharharyati et al., 2012).Karbon aktif ampas tebu digunakan sebagai penyerap zat warna untuk Congo Red (Yoseva et al., 2015) zat warna metilen biru (Utomo et al., 2015), kation basa zat warna (Farahani et al., 2011). Penelitian ini bertujuan untuk (1) mendapatkan informasi mengenai karakteristik karbon aktif meliputi gugus fungsional menggunakan FTIR (Fourier Transform Infra Red) dan luas permukaan dengan menggunakan BET (BrunauerEmmett-Teller), (2) menetukan kondisi optimum karbon aktif dengan dengan variabel waktu, berat, dan $\mathrm{pH}$, dan (3) mengetahui karakteristik adsorpsi isothermal Langmuir yang terjadi dan efektifitas penyerapan karbon aktif dari ampas tebu terhadap zat warna procion merah.

\section{Metode}

Ampas tebu sebanyak $500 \mathrm{~g}$ dibersihkan dan dirajang kecil-kecil, lalu direndam kedalam $\mathrm{NaOH} 6 \%$ selama 24 jam.Hasil rendaman kemudian dicuci dengan air hingga mencapai $\mathrm{pH}$ netral (6-7), lalu dikeringkan dengan menggunakan oven pada temperatur $100^{\circ}-110^{\circ} \mathrm{C}$ selama 24 jam. Ampas tebu yang telah kering digiling dengan menggunakan penggilingan lalu dikarbonisasi pada suhu $450^{\circ} \mathrm{C}$ selama 2 jam, sehingga diperoleh karbon aktif dari 
ampas tebu sebanyak 72,55 g. Karbon yang dihasilkan kemudian dilakukan karakterisasi FTIR di Laboratorium Kimia Organik FMIPA Universitas Gajah Mada dan BET di Laboratorium Kimia Instrumen Universitas Negeri Semarang. Pencarian panjang gelombang maksimum untuk pengukuran zat warna procion merah oleh spektrofotometer UV-Vis dilakukan pada larutan standar berkonsentrasi $7 \mathrm{mg} / \mathrm{L}$ pada panjang gelombang 500-550 nm. Panjang gelombang yang memberikan serapan maksimum diperoleh sebesar $542 \mathrm{~nm}$. Panjang gelombang maksimum ini selanjutnyadigunakan ketika mengukur absorbansi larutan standar procion merah $(0,5,7,10$, 15 , dan $20 \mathrm{mg} / \mathrm{L}$ ) dan larutan dari berbagai perlakukan penelitian.

\subsection{Perlakuan Waktu Kontak}

Karbon aktif yang terbuat dari ampas tebu sebanyak $0,1 \mathrm{~g}$ dimasukan kedalam erlenmeyer yang berisi 50 $\mathrm{mL}$ larutan standar procion merah berkonsentrasi 20 $\mathrm{mg} / \mathrm{L}$. Terdapat lima waktu kontak yang diteliti, sehingga dengan tiga ulangan terdapat total 15 satuan percobaan. Campuran diaduk dengan menggunakan shaker berkecepatan $150 \mathrm{rpm}$ dengan variasi waktu 30 , 60, 90, 120, dan 150 menit, lalu campuran didiamkan selama 15 menit selanjutnya disaring menggunakan kertas saring. Filtrat yang diperoleh diukur absorbansinya dengan menggunakan spektrofotometer UV Vis untuk kemudian dianalisis untuk memperoleh waktu kontak optimum.

\subsection{Perlakuan Berat Karbon Aktif}

Lima buah Erlenmeyer berisi $50 \mathrm{~mL}$ larutan standar procion merah konsentrasi $20 \mathrm{mg} / \mathrm{L}$ ditambahkan karbon aktif dari ampas tebu dengan variasi berat 0,1 , $0,2,, 0,3,0,4$, dan 0,5 g. Dengan tiga ulangan maka terdapat 15 satuan percobaan. Campuran diaduk dengan shaker berkecepatan $150 \mathrm{rpm}$ selama waktu optimum yang diperoleh sebelumnya, campuran didiamkan selama 15 menit kemudian disaring dengan kertas saring.Filtrat yang diperoleh diukur absorbansinya dengan menggunakan spektrofotometer UV Vis sehingga diperoleh berat optimum karbon aktif.

\subsection{Perlakuan $\mathrm{pH}$}

Karbon aktif dari ampas tebu dengan berat optimum sebagaimana hasil penelitian perlakuan berat karbon aktif dimasukan kedalam erlenmeyer yang berisi $50 \mathrm{~mL}$ larutan standar procion merah berkonsentrasi $20 \mathrm{mg} / \mathrm{L}$. Campuran ditetesi $\mathrm{HCl} 1 \mathrm{M}$ atapun $\mathrm{NaOH} 1 \mathrm{M}$ agar diperoleh $\mathrm{pH} 4,5,6,7,8$, dan 9.Dengan tiga ulangan, maka terdapat 18 satuan percobaan. Campuran diaduk dengan shaker berkecepatan $150 \mathrm{rpm}$ selama waktu kontak yang dihasilkan pada proses sebelumnya, lalu didiamkan selama 15 menit dan disaring. Filtrat yang diperoleh diukur absorbansinya dengan menggunakan spektrofotometer UV Vis sehingga diperoleh $\mathrm{pH}$ optimum karbon aktif.

\subsection{Penentuan Kapasitas Adsorpsi}

Karbon aktif dari ampas tebu sebanyak $0,1 \mathrm{~g}$ dikontakan dengan $50 \mathrm{~mL}$ variasi larutan zat warna procion merah berkonsentrasi $100 \mathrm{mg} / \mathrm{L} ; 200 \mathrm{mg} / \mathrm{L}$; $300 \mathrm{mg} / \mathrm{L} ; 400 \mathrm{mg} / \mathrm{L} ; 500 \mathrm{mg} / \mathrm{L}$. Campuran kemudian diaduk dengan menggunakan shaker berekecapan 150 rpm selama waktu kontak optimum, lalu didiamkan selama 15 menit dan disaring. Filtrat yang diperoleh diukur absorbansinya dengan menggunakan spektrofotometer UV Vis. Penentuan kapasitas adsorpsi karbon aktif dari ampas tebu terhadap larutan zat warna procion merah dilakukan dengan menggunakan model adsorpsi isotermal Langmuir.

\subsection{Aplikasi Karbon Aktif Terhadap Limbah Cair Industri Songket Pada Kondisi Optimum}

Limbah cair industri songket sebanyak $5 \mathrm{~mL}$ diencerkan dengan menambahkan $\mathrm{HCl} 1 \mathrm{M}$ ataupun $\mathrm{NaOH} 1 \mathrm{M}$ hingga $\mathrm{pH}$ optimum pada labu takar 50 $\mathrm{mL}$. Larutan ini kemudian masing-masing ditambahkan karbon ampas tebu sebanyak berat optimum. Masingmasing campuran dicampur dengan menggunakan shaker selama waktu optimum, kemudian disaring dengan menggunakan kertas saring sehingga diperoleh filtrat kemudian dilakukan pengukuran adsorbansinya dengan spektrofotometer UV-Vis.

\section{Hasil dan Pembahasan}

\subsection{Hasil Karakterisasi Karbon Aktif Ampas Tebu dengan Menggunakan FTIR}

Ampas tebu memiliki komposisi kimia yang didominasi oleh selulosa yaitu sekitar $46 \%$ (Fabon et al. 2013).Selulosa yang terkandung dalam ampas tebu menentukan kapasitas adsorpsi, dimana pada selulosa terkandung gugus karboksil (-COO-) dan hidroksil ($\mathrm{OH})$ (Li et al. 2016). Sebagaimana disajikan pada Gambar 1, karbon aktif ampas tebu memiliki gugus fungsi -CO- pada daerah serapan $1705,07 \mathrm{~cm}^{-1}$ dan gugus fungsi $-\mathrm{OH}$ pada daerah serapan $3410,15 \mathrm{~cm}^{-1}$.

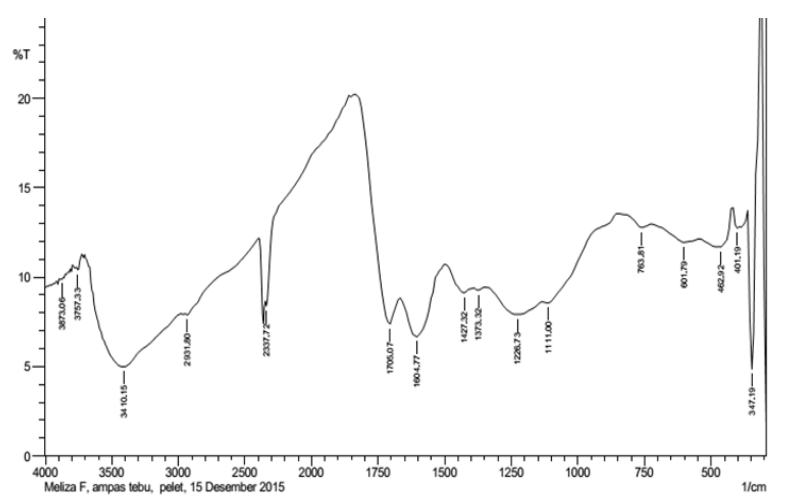

Gambar 1. Spektrum serapan gugus fungsional pada karbon aktif dari ampas tebu. 


\subsection{Hasil Karakterisasi Karbon Aktif Ampas Tebu dengan BET}

Permukaan karbon memiliki karakter yang unik, yaitu struktur penyerap yang menentukan daya serapnya (Bansal dan Golan, 2005). Karbon aktif dari ampas tebu memiliki luas permukaan $29,21 \mathrm{~m}^{2} / \mathrm{g}$ dan diameter pori $30,17 \AA$. Ukuran pori ini tergolong mesopori. Karbon aktif dengan dominasi mesopori umumnya digunakan sebagai penyerap molekulmolekul besar seperti zat warna (Setianingsih et al., 2008).

\subsection{Pengaruh Waktu Kontak Karbon Aktif Terhadap Penyerapan Zat Warna Procion Merah}

Waktu kontak merupakan salah satu variabel kondisi optimum adsorpsi yang dicapai oleh karbon aktif, waktu kontak optimum dicapai ketika kesetimbangan adsorben tidak mampu lagi menyerap adsorbat. Pada Gambar 2 menunjukkan bahwa karbon aktif dari ampas tebu memiliki waktu kontak 90 menit dengan daya serapnya sebesar $6,90 \mathrm{mg} / \mathrm{g}$ dan efesiensi penyerapan sebesar $69,04 \%$. Setelah 90 menit waktu kontak, daya serap relative tidak meningkat lagi.

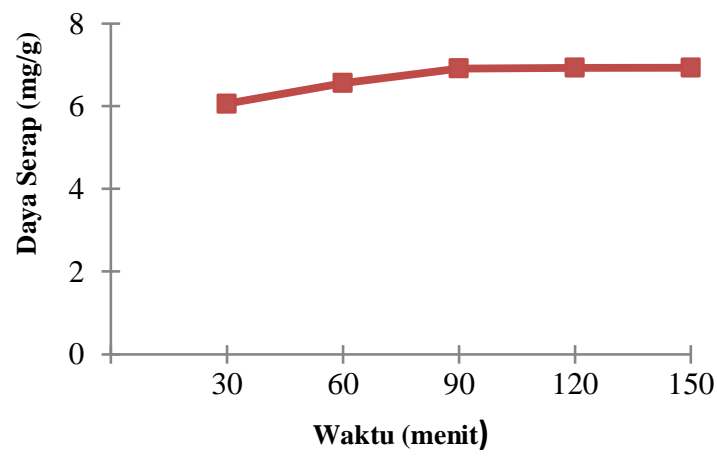

Gambar 2. Grafik pengaruh waktu kontak terhadap daya serap oleh karbon aktif dari ampas tebu.

Hal ini menunjukkan 1g karbon aktif ampas tebu mampu mengadsorpsi $6,9 \mathrm{mg}$ zat warna procion merah dengan persentase penurunan konsentrasi sebesar $69 \%$ dari konsentrasi awal zat warna.

\subsection{Pengaruh Berat Karbon Aktif terhadap Penyerapan Zat Warna Procion Merah}

Efisiensi penyerapan dipengaruhi oleh perbandingan adsorben terhadap adsorbat. Oleh karena itu dilakukan penentuan berat optimum dari karbon aktif ampas tebu dengan memvariasikan berat yakni 0,$1 ; 0,2 ; 0,3 ; 04$; dan 0,5 gram. Hasil yang didapat, sebagaimana disajikan pada Gambar 3 bahwa diperoleh berat optimum karbon aktif $0,1 \mathrm{~g}$ dengan daya serap 6,88 $\mathrm{mg} / \mathrm{g}$

Jumlah adsorben yang ditambahkan mempengaruhi efisiensi penyerapan, dimana hal ini sebanding dengan jumlah partikel dan luas permukaan karbon aktif sehingga menyebabkan sisi aktif adsorpsi dan efisiensi penyerapan meningkat sementara daya serap menurun dengan bertambahnya penambahan karbon aktif.
Efisiensi serapan penyerapan sebesar $68,84 \%$ seperti pada Gambar 4.

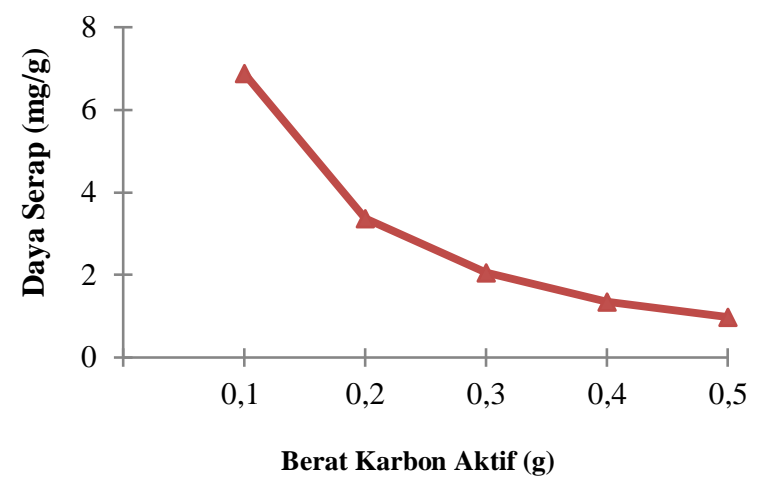

Gambar 3. Grafik pengaruh berat karbon aktif terhadap daya serap oleh karbon aktif dari ampas Tebu.

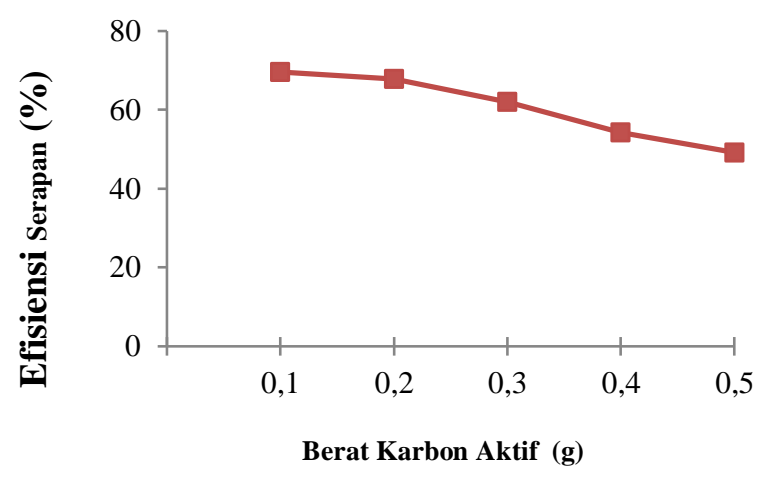

Gambar 4. Efisiensi serapan karbon aktif dari ampas tebu.

Ada kemungkinan daya serap meningkat dan belummencapai kondisi optimum, dikarenakan adanya kemungkinan tumbukan antar muka serbuk yang belum intensif sehingga menyebabkan semakin besar kesempatan serbuk berinteraksi dengan zat warna apabila adsoben ditambahkan lebih sedikit.

\subsection{Pengaruh $p H$ Larutan terhadap Penyerapan Zat Warna Procion Merah}

Nilai $\mathrm{pH}$ optimum adalah $\mathrm{pH}$ dimana adsoben memiliki kemampuan menyerap adsorbat tertinggi, $\mathrm{pH}$ awal larutan sebelum ditambahkan $\mathrm{NaOH}$ ataupun $\mathrm{HCl}$ adalah sebesar 5,37. Pada Gambar 5 menunjukkan bahwa karbon aktif dari ampas tebu memiliki serapan optimum pada $\mathrm{pH} 5$ dengan daya serap sebesar 7,66 $\mathrm{mg} / \mathrm{g}$ serta efisiensi serapan $76 \%$. pH memainkan peran penting pada proses penyerapan khususnya pada kapasitas adsorpsi, dimana akan terjadi proses pertukaran ion yang berasal dari gugus reaktif zat warna dengan luas permukaan adsorben. Interaksi antara adsorben dan zat warna dapat terjadi karena ikatan hidrogen yang berperan pada proses adsorpsi.

Penurunan daya serap disebabkan oleh adanya pertukaran antara adsorben dan adsorbat, luas permukaan adsorben dan interaksi antara adsorben dan zat warna merupakan faktor dalam menentukan daya serap. 


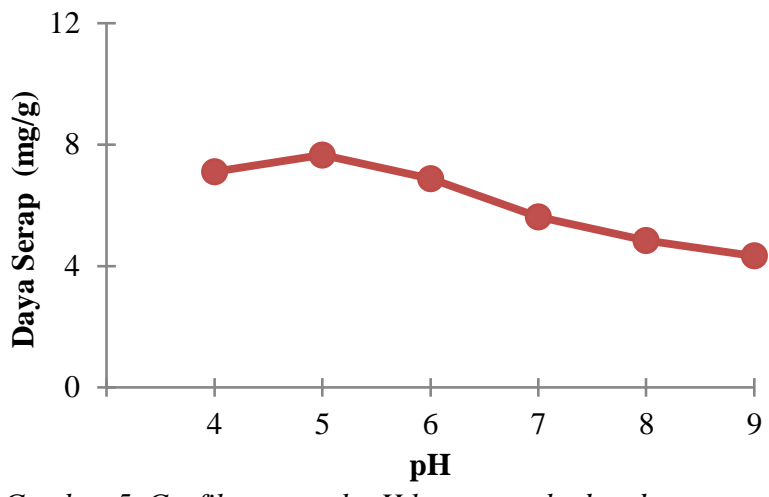

Gambar 5. Grafik pengaruh pH larutan terhadap daya serap karbon aktif dari ampas tebu.

\subsection{Penentuan Adsorpsi Isotermal Langmuir}

Adsorpsi isotermal memberikan informasi menganai adsorbat, adsorben dan proses penyerapan yang terjadi. Model adsorpsi isotermal digunakan untuk menentukan daya serap dan menunjukkan adanya korelasi antara aktivitas adsorbat dengan jumlah zat teradsorpsi pada temperatur konstan. Grafik Isoterm Langmuir (Gambar 6) dibuat dengan memplotkan $C$ sebagai sumbu $X$ dengan $\mathrm{C} / \mathrm{Q}$ sebagai sumbu $\mathrm{Y}$ dimana serapan maksimum sebesar $0,45 \mathrm{mg} / \mathrm{g}$ dan energi serapan 4,35 $\mathrm{kJ} / \mathrm{mol}$

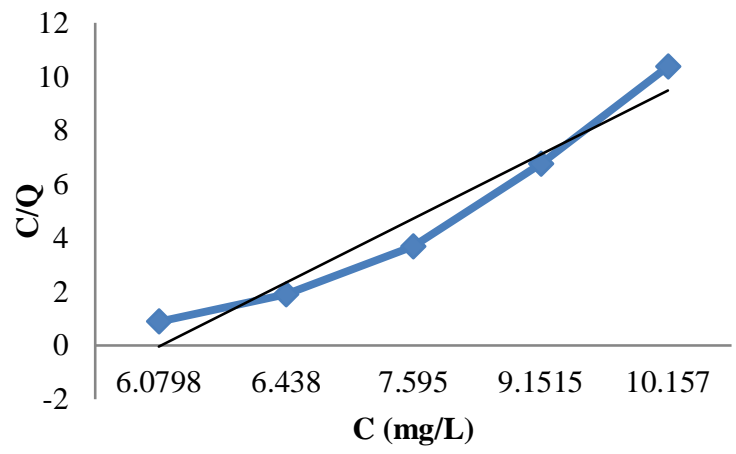

Gambar 6. Grarik isoterm adsorpsi langmuir karbon aktif dari ampas tebu.

Adsorpsi isotermal Langmuir memiliki asumsi dimana adsorben mempunyai permukaan yang homogen dan hanya dapat menyerap satu molekul untuk tiap molekul adsobennya, sehingga setiap area permukaan memiliki energi ikatan yang sama.

\subsection{Aplikasi Karbon Aktif Dari Ampas Tebu dan Eceng Gondok Pada Limbah Cair Industri Songket}

Kondisi optimum penyerapan diperlukan untuk mengetahui daya serap limbah cair dari industri songket oleh karbon aktif dari ampas tebu. Konsentrasi zat warna procion merah limbah cair dari industri songket sebesar 969,28 $\mathrm{mg} / \mathrm{L}$, namun ketika ditambahkan karbon aktif pada kondisi waktu kontak 90 menit, berat karbon aktif $0,1 \mathrm{~g}$, dan $\mathrm{pH} 5$ terjadi penurunan konsentrasi $229,87 \mathrm{mg} / \mathrm{L}$ dengan efektifitas penyerapan sebesar $76,3 \%$.

\section{Kesimpulan}

Karbon aktif dari ampas tebu memiliki gugus fungsional -CO- dan - $\mathrm{OH}$ dan termasuk karbon aktif mesopori. Adsorpsi zat warna procion merah oleh karbon aktif dari ampas tebu memiliki kondisi optimum waktu kontak ke 90 menit, berat adsorben sebesar 0,1 g, pH optimum 5. Serapan isotermal Langmuir menunjukkan serapan maksimum $0,45 \mathrm{mg} / \mathrm{g}$ dan energi serapan 4,35 $\mathrm{kJ} / \mathrm{mol}$. Penelitian ini menunjukkan karbon aktif dari ampas tebu dapat digunakan untuk mengurangikadar zat warna procion merah dalam limbah cair industri songket.

\section{Saran}

Efisiensi penyerapan yang dilakukan oleh karbon aktif terhadap larutan zat warna procion merah dapat ditingkatkan dengan melakukan perbandingan adsorben terhadap adsorbat yang lebih tinggi.

\section{Daftar Pustaka}

[1] Bansal, C. R., dan M. Goyal, 2005. Activated Carbon Adsorption. CRC Press, Boca Raton.

[2] Fabon, M. B., G. J. Legaspi, K. Leyesa, M. C. Macawile, 2013. Removal of Basic Dye in Water Matrix Using Actived Carbon From Sugarcane Bagasse. International Conference on Innovations in Engineering and Technology, pp. 198-201.

[3] Farahani, M., S. R. S. Abdullah, S. Hosseini, S. Shojaeipour, M. Kashisaz, 2011. Adsorption-based Cationic Dyes using the Carbon Active Sugarcane Bagasse. Procedia Environmental Sciences 10, pp. $203-208$.

[4] Hariani, P. L., 2013. Pengolahan limbah cair industri songket menggunakan komposit $\mathrm{Fe}_{3} \mathrm{O}_{4}$ karbon aktif dari cangkang kelapa sawit.Disertasi. Program Pascasarjana, Universitas Sriwijaya, Palembang.

[5] Kusharharyati, T Y., K. W. Deddy, A. Fahmi, 2012. Pengolahan Limbah Pewarnaan Konveksi dengan Bantuan Adsorben Ampas Tebu dan Activated Sludge. Simposium Nasional RAPI XI FT UMS, pp. 51-54.

[6] Li, F., K. Shen, X. Long, J. Wen, X. Xie., X. Zeng, Y. Liang, Y. Wei, Z. Lin, Huang, R. Zhong, 2016. Preparation and Characterization of Biochars from Eichornia crassipes for Cadmium Removal in Aqueous Solutions. Journalpone, pp. 113.

[7] Purwaningrum, W., L. H. Poedji, N. T. Khanizar, 2013. Adsorpsi Zat Warna procion Merah Pada Limbah Cair Industri Songket Menggunakan Kitin dan Kitosan. Prosiding Seminar FMIPA Universitas Lampung, pp. 423-427.

[8] Said, M., 2008. Pengolahan Limbah Cair Hasil Pencelupan Benang Songket dengan Metode Filtrasi dan Adsoprsi. Jurnal Penelitian Sains 11, pp. 479-480.

[9] Setianingsih, T., Hasanah, U., Darjito, 2008. Kajian Pengaruh Temperatur Aktivasi dengan $\mathrm{NaOH}$ Terhadap Karakter Karbon Aktif Mesopori Berbahan Dasar Limbah Kompleks Lumpur Industri Tekstil Indo. J. Chem 8, pp. 348-352.

[10] Utomo, H. D., R. Y. N. Phoon, Z. Shen, L. H. Ng, Z. B Lim, 2015. Removal of Methylen Blue Using Chemical Modified Sugarcane Bagasse. Natural Resources 20, pp. 209-220.

[11] Yoseva, P. L., M. Akmal, S. Halida, 2015. Pemanfaatan Limbah Ampas Tebu Sebagai Adsorben untuk Peningkatan Kualitas Air Gambu. JOM FMIPA 2: 56-63. 